\title{
Seroepidemiological Prevalence of Human Brucellosis in Gorgan and Dasht, Iran
}

\section{A R T I C L E I N F O}

Article Type

Original Research

Authors

Leila Fozouni, $P h D^{1^{*}}$

Zeynab Teimori, $M S c^{1}$

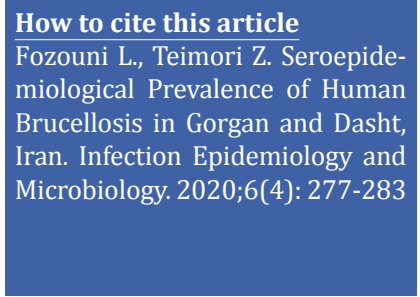

${ }^{1}$ Department of Biology, Gorgan Branch, Islamic Azad University, Gorgan, Iran

\section{* Correspondence}

Address: Department of Biology, Gorgan Branch, Islamic Azad University, Gorgan, Iran.

lili_kia@yahoo.com

\section{Article History}

Received: October 05,2020

Accepted: November 05,2020

Published: November 19,2020

\section{A B S T R A C T}

Background: Brucellosis is an important zoonotic disease with significant economic and public health consequences. This study aimed to investigate the seroepidemiological prevalence of human brucellosis in Gorgan and Dasht, Northeastern Iran during one year. Materials \& Methods: In this study, 153 brucellosis-suspected cases who were referred to the health centers of Gorgan and surrounding villages from April 2017 to March 2018, were included. Two serological assays (Wright and 2-mercaptoethanol) were performed on all sera taken from patients. Data were analyzed by SPSS software (version 23) using Chi-square test and independent t-test. A $p$-value less than .05 was considered as statistically significant. Findings: Of 153 suspected cases, 62 cases (40.5\%) were positive for brucellosis, among whom 39 cases (62.9\%) were men, and 41 cases $(66 \%)$ were $17-38$ years old. The highest prevalence rate of brucellosis was observed in rural men (69.5\%) as well as in those consuming raw cheese $(35.5 \%)$ and being in direct contact with livestock $(27.5 \%)$. Furthermore, the frequency of the disease was significantly higher in the summer. The incidence rate of the disease was significantly associated with season, history of contact with livestock, and the type of dairy product consumed $(p<.05)$.

Conclusion: The prevalence of brucellosis is higher in rural areas of Gorgan, particularly among farmers and livestock keepers. Providing training and raising awareness of these individuals as well as developing strategic health plans regarding the consumption of unpasteurized dairy products could help reduce the incidence of brucellosis.

Keywords: Brucellosis, Epidemiology, Serology.

\section{CITATION LINKS}

[1] Celebi G, Kulah C, Kilic S, Ustundag G. Asymptomatic Brucella bacteraemia and... [2] Piroozi B, Moradi Gh, Safari H, Mohamadi P, Alinia C, Shirzadi MR, et al. Incidence, mortality, and ... [3] Franco MP, Mulder M, Gilman RH, Smits HL. Human ... [4] Musallam II, Abo-Shehada MN, Hegazy YM, Holt HR, Guitian FJ. Systematic review of ... [5] Wasee R, Waqas M, Shah M. Epidemiology of bovine brucellosis- A ... [6] Sofian M, Aghakhani A, Velayati AA, banifazl M, eslamifar A, ramezani A. Risk factors for ... [7] National guideline for brucellosis control. Ministry of Health and Medical ... [8] Rostami H, Mehrabi Tavana A, Tavakoli HR, Tutunchian M. Prevalence ... [9] Doganay M, Aygen B. Human brucellosis: An ... [10] Zeainali M, Shirzadi M, Hajrasouliha H. National manual for ... [11] Pappas G, Papadimitriou P, Akritidis N, Christou L, Tsianos EV. The new ... [12] Shakurnia A, Ghasemzadeh A, Afra M, Sarizadeh G, Javidan S, Khodadadi A, et al. The ... [13] Elbeltagy KE. An epidemiological profile of brucellosis in tabuk ... [14] Hosseini SM, Changizi R, Razavimehr SV, Moshrefi A, amani R, Aghajanikhah MH. Investigation of ... [15] Parlak M, Akbayram S, Dogan M, Tuncer O, Bayram Y, Ceylan N, et al. Clinical ... [16] Tumwine G, Matovu E, Kabasa JD, Owiny DO, Majalija S. Human brucellosis: sero-prevalence and ... [17] Kayaaslan B, Bastug A, Aydin E, Akinci E, But A, Aslaner H, et al. A long-term survey of ... [18] Pakzad R, Barati M, Moludi J, Barati H, Pakzad I. Epidemiology of brucellosis in the North and North-West ... [19] karimi A, karimi B. Epidemiological status of brucellosis in Abadeh ... [20] Cui LL, Tan WW, Hang JH, Zhou WZ, Tan ZM, Zhou JG, et al. A cross-sectional survey on the prevalence of brucellosis among workers in Jiangsu province, 2012. Zhonghua Liu Xing...[21] Farahani S, Shah Mohamadi S, Navidi I, Sofian M. An investigation of the epidemiology of brucellosis in Arak city, Iran, (2001-2010). J Arak... [22] Hashtarkhani S, Akbari M, Jarahi L, Etminan K. Epidemiological characteristics and trend of incidence of human brucellosis in Razavi Khorasan... [23] Obradovic Z, Velic R. Epidemiological characteristics of brucellosis in Federation of Bosnia and ... [24] Akhvlediani T, Bautista CT, Garuchava N, Sanodze L, Kokaia N, Malania L, et al. Epidemiological and clinical features of brucellosis in the country of Georgia. PLoS... [25] Li MT, Sun GQ, Zhang WY, Jin Z. Model-based evaluation of strategies to control brucellosis in... [26] Akbayram S, Dogan M, Akgun C, Peker E, Parlak M, Oner AF. An analysis of children with brucellosis associated with isolated thrombocytopenia. Clin Appl Thromb... 


\section{Introduction}

Brucellosis is a common zoonotic disease, which is of great health, economic, and social importance. The disease could be transmitted to humans mainly through direct contact with livestock and consumption of unpasteurized dairy products. The main causative agents of this infection are Brucella suis, B. canis, $B$. abortus, and B. melitensis, which are transmitted to humans via pigs, dogs, cattle, and sheep, respectively ${ }^{[1]}$. Animals with brucellosis usually have an abortion in the first period of pregnancy, which is accompanied by uterine secretions contaminating the environment, farms, and pastures. Periodic excretion of bacteria through animal milk and uterine secretions in asymptomatic animals poses risks to other animals as well as humans ${ }^{[2]}$. The disease symptoms in humans include fatigue, lethargy, chills, fever, sweating, loss of appetite, headache, back pain, and psychological problems. The disease is more common in people working in slaughterhouses and livestock farms as well as in those dealing with meat products, such as butchers, veterinarians, and shepherds. Currently, there is no vaccine that could provide long-term immunity in humans, but a few live smooth attenuated vaccines are used for livestock immunization. Many efforts have been made to eradicate the disease in cattle and sheep around the world ${ }^{[3-4]}$. According to the World Health Organization estimates, about half a million people are infected with the disease each year. About 45,000 cases occur annually in the Eastern Mediterranean region. However, these statistics do not reflect the actual number of cases as only one in every five cases of the disease is identified ${ }^{[5-6]}$. Generally, there is no accurate estimate of the global prevalence of brucellosis due to the insufficient data about the disease incidence or the lack of diagnostic facilities in many countries.

In Iran, the prevalence rate of brucellosis was increasing in the 1980s but decreased from 170 to 24 cases per 10,000 people by the late 1990s. Following the promotion of the disease surveilling and reporting system in the country, the prevalence rate of brucellosis had an increasing trend until the successful vaccination coverage of livestock. According to the Disease Management Center of Iran, the number of brucellosis cases increased by $70 \%$ from 12,248 cases in 2010 to 20,117 cases in 2014. Unfortunately, Iran is among the countries with the highest incidence rate of brucellosis. Lowering the incidence rate of brucellosis in livestock would consequently reduce the risk of transmission to humans [7-9].

Objectives: Considering the significant health and economic burden of brucellosis, the present study aimed to investigate the seroepidemiological prevalence of this disease in Gorgan (Northeast of Iran) and surrounding villages.

\section{Materials and Methods}

In this descriptive-analytical study, blood samples were taken from 153 brucellosissuspected people (age range: 17-88 years) who were referred to the health centers and laboratories of Gorgan (Iran) from April 2017 to March 2018. After obtaining consent, all the participants completed a questionnaire about age, sex, occupation, dietary habits, place of residence, season of admission, history of contact with livestock, and family history. Then blood specimens were taken from the patients, and their serum was separated. Rose Bengal, sero-agglutination in tube (Wright), and 2-mercaptoethanol (2ME) tests were performed on the serums. All the participants had titers of $\geq 1: 80$ and $\geq 1: 40$ in Wright and 2ME tests, respectively [10-11]. Collected data were analyzed by SPSS software (version 23) using chi-square and independent t-tests. A $p$-value less than .01 was considered as statistically significant. 


\section{Findings}

Of 153 suspected cases, 62 cases (40.5\%) were positive for brucellosis, of whom 39 cases (62.9\%) were men, and 41 cases (66\%) were 17-38 years old. In addition, there was no positive sample among the samples taken from people over 80 years old. There was a significant difference in the prevalence rate of brucellosis between rural (58\%) and urban $(42 \%)$ areas $(p=.025)$. The prevalence rate of brucellosis was higher in rural men (69.5\%) and urban women (61\%).

The disease was more prevalent in summer
(59.5\%) and spring (27.5\%) ( $p=.004)$. Family history of brucellosis was positive, negative, and not defined in 23 (37\%), 28 (45\%), and $11(18 \%)$ cases, respectively ( $p=.038)$. In addition, history of contact with livestock was positive, negative, and not defined in 19 (30.5\%), 23 (37\%), and 20 (32.5\%) cases, respectively $(p=.019)$. The most common clinical symptoms in patients were fever (76\%), back and muscle pain (69.5\%), weight loss (53.5\%), and loss of appetite (46.5\%). Moreover, $19.5 \%$ of the cases were asymptomatic $(p=.076)$.

Table 1) Relative frequency of brucellosis based on the type of dairy products consumed

\begin{tabular}{|c|c|c|c|c|c|c|}
\hline \multirow{3}{*}{ Dairy Product } & \multicolumn{4}{|c|}{ Gender } & \multirow{2}{*}{\multicolumn{2}{|c|}{ Total }} \\
\hline & \multicolumn{2}{|c|}{ Men } & \multicolumn{2}{|c|}{ Women } & & \\
\hline & Number & Percent (\%) & Number & Percent (\%) & Number & Percent (\%) \\
\hline Ice cream & 8 & 20.5 & 3 & 13 & 11 & 17.5 \\
\hline Raw cheese & 13 & 33.5 & 9 & 39 & 22 & 35.5 \\
\hline Cream & 7 & 18 & 2 & 9 & 9 & 14.5 \\
\hline Raw milk & 11 & 28 & 9 & 39 & 20 & 32.5 \\
\hline
\end{tabular}

Table 2) Frequency of brucellosis based on occupation

\begin{tabular}{|c|c|c|c|c|c|c|}
\hline \multirow{3}{*}{ Occupation } & \multicolumn{4}{|c|}{ Gender } & \multirow{2}{*}{\multicolumn{2}{|c|}{ Total }} \\
\hline & \multicolumn{2}{|c|}{ Men } & \multicolumn{2}{|c|}{ Women } & & \\
\hline & Number & Percent (\%) & Number & Percent (\%) & Number & Percent (\%) \\
\hline $\begin{array}{l}\text { General } \\
\text { worker }\end{array}$ & 4 & 10 & 0 & 0 & 4 & 6.5 \\
\hline Farmer & 6 & 15.5 & 4 & 17.5 & 10 & 16 \\
\hline Self-employed & 7 & 18 & 6 & 26 & 13 & 21 \\
\hline $\begin{array}{l}\text { Livestock } \\
\text { keeper }\end{array}$ & 12 & 30.5 & 5 & 21.5 & 17 & 27.5 \\
\hline Homemaker & 0 & 0 & 6 & 26 & 6 & 9.5 \\
\hline Other & 5 & 26 & 2 & 9 & 7 & 19.5 \\
\hline
\end{tabular}




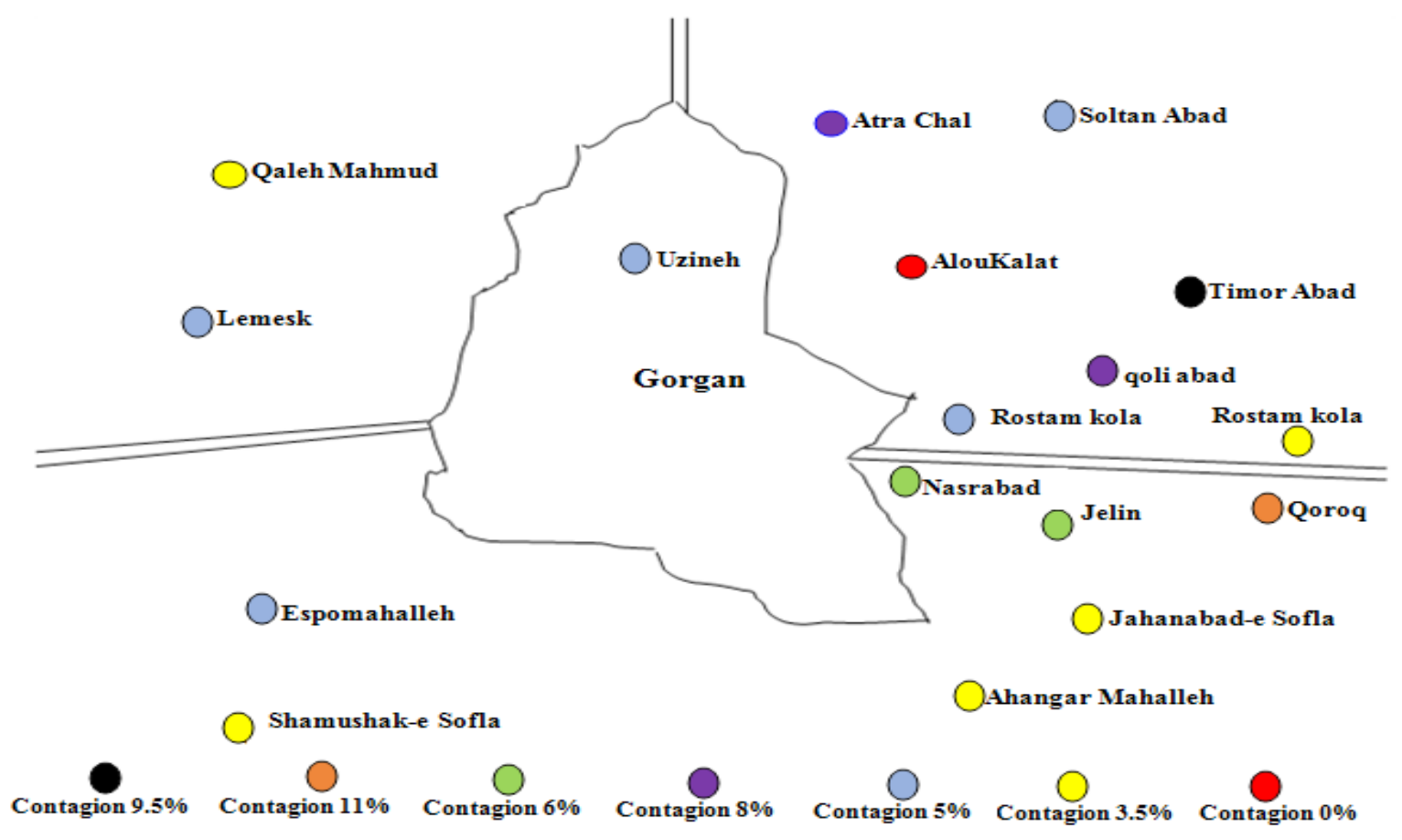

Figure 1) Relative frequency of brucellosis in villages around Gorgan in 2018

As shown in Table 1, the highest incidence rate of brucellosis was observed in those consuming raw cheese, and lowest incidence rate was observed in those consuming cream ( $p=.001)$. The highest incidence rate of brucellosis was observed in livestock keepers (27.5\%), and the lowest incidence rate $(6.5 \%)$ was observed in general workers ( $p=109$ ) (Table 2).

Overall, 23 (37\%) and 32 (51.5\%) cases were brucellosis positive based on the Write and 2ME tests results, respectively (Figures 2 and 3).

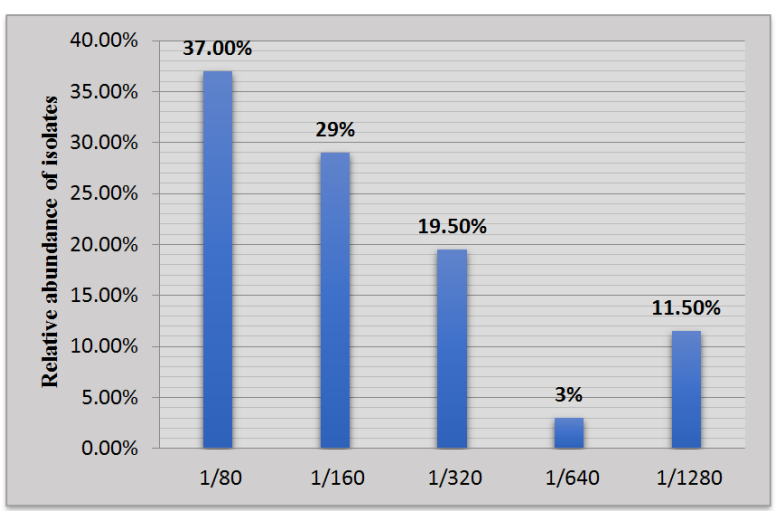

Figure 2) Frequency of brucellosis cases found to be positive using the $2 \mathrm{ME}$ test

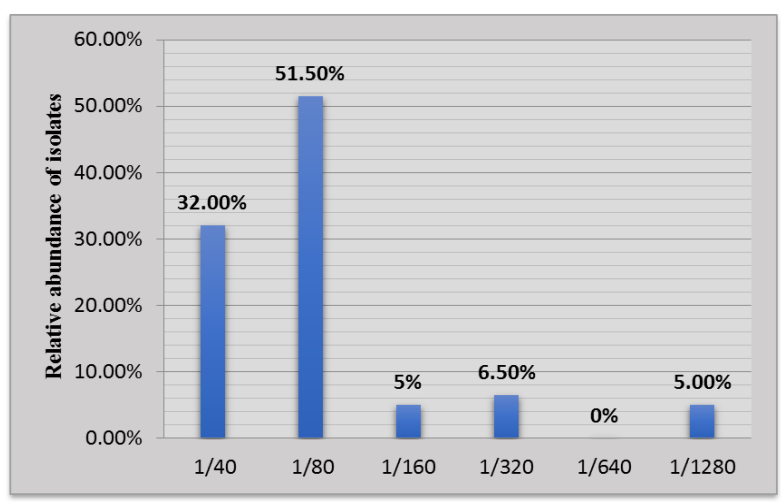

Figure 3) Frequency of brucellosis cases found to be positive using the Wright test

\section{Discussion}

Brucellosis has always been considered an important health and economic problem. The infection is difficult to diagnose due to nonspecific signs and symptoms, especially in endemic areas. Although polymerase chain reaction is more specific for diagnosing brucellosis, the disease is often diagnosed based on the serological findings. Accordingly, in this study, 62 (40.5\%) brucellosis cases 
were identified based on the results of the Wright and 2ME tests. In a previous study in Iran (2014), the seroprevalence of brucellosis was reported to be $56 \%{ }^{[12]}$. The difference in the seroprevalence rates between the current and the mentioned studies could be attributed to the factors such as study season, geographical area, and employment status of the subjects.

In line with the present study findings, previous studies in Saudi Arabia [13], Iran [14], Turkey [15], Uganda [16], and the United Kingdom ${ }^{[17]}$ have reported that the prevalence of brucellosis was higher in men than in women. It seems that brucellosis occurs more commonly in men as a work-related disease. Previous studies in Iran have also reported contact with livestock as a main cause of brucellosis [18-19]. Cui et al. also reported occupation as a risk factor for brucellosis [20]. In the present study, the prevalence of brucellosis was higher in rural areas, which is consistent with the results of the previous serological studies in Iran [14, 21-22].

According to the obtained results, brucellosis was more common in those consuming raw milk and cheese. In 2010, a study in Bosnia and Herzegovina indicated that brucellosis mainly occurred due to contact with infected animals and consumption of unpasteurized dairy products ${ }^{[23]}$. Similarly, studies in Georgia ${ }^{[24]}$ and China ${ }^{[25]}$ have reported consumption of unpasteurized dairy products as the most important cause of brucellosis.

Similar to the previous studies findings [26], fever, musculoskeletal pain, and fatigue were identified in this study as the most common symptoms of brucellosis; therefore, serological evaluation of individuals with these symptoms is recommended.

\section{Conclusion}

The prevalence of brucellosis is higher in farmers and livestock keepers, particularly those living in rural areas of Gorgan, northeastern Iran. Public education and awareness raising might be effective in reducing the incidence of brucellosis in the studied area. Given that the consumption of local/unpasteurized dairy products may bean important route for the disease transmission to humans, it is essential to employ more strict policies for controlling the distribution of such products.

Acknowledgements: This article was extracted from MSc thesis conducted by Zeynab Teimori and supported by the Research Council of the Islamic Azad University of Gorgan, Iran. The authors are grateful to all those assisting them in this study.

Ethical Permissions: Authors hereby declare that all ethical standards have been respected in the preparation of the submitted article.

Conflicts of Interests: None declared.

Authors' Contribution: Conceptualization: LF; Data curation and formal analysis: LF; Investigation: LF, ZT; Methodology and project administration: LF, ZT; Supervision: LF; Validation: LF; Writing of original draft: LF, ZT; Writing, reviewing, and editing: LF, ZT. Fundings: No financial interests related to the content of this manuscript are declared. Consent to participate: A written informed consent was obtained from all patients.

\section{References}

1. Celebi G, Kulah C, Kilic S, Ustundag G. Asymptomatic Brucella bacteraemia and isolation of Brucella melitensis biovar 3 from human breast milk. Scand J Infect Dis. 2007;39(3):205-8.

2. Piroozi B, Moradi Gh, Safari H, Mohamadi P, Alinia C, Shirzadi MR, et al. Incidence, mortality, and burden of human brucellosis and its geographical distribution in Iran during2009-2015. Iran J Public Health. 2019;48(1):20-7.

3. Franco MP, Mulder M, Gilman RH, Smits 
HL. Human brucellosis. Lancet Infect Dis. 2007;7(12):775-86.

4. Musallam II, Abo-Shehada MN, Hegazy YM, Holt HR, Guitian FJ. Systematic review of brucellosis in the Middle East: Disease frequency in ruminants and humans and risk factors for human infection. Epidemiol Infect. 2016;44(4):671-85.

5. Wasee R, Waqas M, Shah M. Epidemiology of bovine brucellosis- A review of literature. Veterinaria. 2014;1(2):16-19.

6. Sofian M, Aghakhani A, Velayati AA, banifazl M, eslamifar A, ramezani A. Risk factors for human brucellosis in Iran: A case-control study. Int J Infect Dis. 2008;12(2):157-61.

7. National guideline for brucellosis control. Ministry of Health and Medical Education Health Deputy Center of Communicable Diseases Control Zoonoses Office; 2012.

8. Rostami H, Mehrabi Tavana A, Tavakoli HR, Tutunchian M. Prevalence study of brucellosis in Iranian military forces during 2001-2009. J Health Pol Sustainable Health. 2015;2(2):191-4.

9. Doganay M, Aygen B. Human brucellosis: An overview. Int J Infect Dis. 2003;7(3):173-82.

10. Zeainali $M$, Shirzadi $M$, Hajrasouliha $H$. National manual for brucellosis control. Iran, Tehran. Raz Nahan. 2013;34(1):63-9.

11. Pappas G, Papadimitriou P, Akritidis N, Christou L, Tsianos EV. The new global map of human brucellosis. Lancet Infect Dis. 2006;6(2):91-9.

12. Shakurnia A, Ghasemzadeh A, Afra M, Sarizadeh G, Javidan S, Khodadadi A, et al. The Seroprevalence of brucellosis among blood donors referred to blood centers of Khuzestan province. Sci J Iran Blood Transfus Organ. 2014;11(3):180-9.

13. Elbeltagy KE. An epidemiological profile of brucellosis in tabuk province, Saudi Arabia. East Mediterr Health J. 2001;7(4-
5):791-8.

14. Hosseini SM, Changizi R, Razavimehr SV, Moshrefi A, amani R, Aghajanikhah $\mathrm{MH}$. Investigation of the brucellosis epidemiology in Quchan 2013. Beyhagh. 2016;20(35):32-9.

15. Parlak M, Akbayram S, Dogan M, Tuncer O, Bayram Y, Ceylan N, et al. Clinical manifestations and laboratory findings of 496 children with brucellosis in Van, Turkey. Pediatr Int. 2015;57(4):586-9.

16. Tumwine G, Matovu E, Kabasa JD, Owiny DO, Majalija S. Human brucellosis: seroprevalence and associated risk factors in agro-pastoral communities of Kiboga District, Central Uganda. BMC Public Health. 2015;15(1):1-8.

17. Kayaaslan B, Bastug A, Aydin E, Akinci E, But A, Aslaner H, et al. A long-term survey of brucellosis: Is there any marker to predict the complicated cases? Infect Dis. 2016;48(3):215-21.

18. Pakzad R, Barati M, Moludi J, Barati H, Pakzad I. Epidemiology of brucellosis in the North and North-West Iran. Paramed Sci Mil Health. 2016;11(1):17-23. 19. karimi A, karimi B. Epidemiological status of brucellosis in Abadeh county, Fars province, Iran in 2011-2017. J Community Health Res. 2018;7(3):183-91.

19. karimi A, karimi B. Epidemiological status of brucellosis in Abadeh county, Fars province, Iran in 2011-2017. J Community Health Res. 2018;7(3) :183-91.

20. Cui LL, Tan WW, Hang JH, Zhou WZ, Tan ZM, Zhou JG, et al. A cross-sectional survey on the prevalence of brucellosis among workers in Jiangsu province, 2012. Zhonghua Liu Xing Bing Xue Za Zhi. 2013;34(7):686-9.

21. Farahani S, Shah Mohamadi S, Navidi I, Sofian M. An investigation of the epidemiology of brucellosis in Arak city, Iran, (2001-2010). J Arak Uni Med Sci. 2012;14(7):49-54. 
22. HashtarkhaniS, AkbariM,JarahiL,Etminan K. Epidemiological characteristics and trend of incidence of human brucellosis in Razavi Khorasan province. MJMS. 2015;58(9):531-8.

23. Obradovic Z, Velic R. Epidemiological characteristics of brucellosis in Federation of Bosnia and Herzegovina. Croat Med J. 2010;51(4):345-50.

24. Akhvlediani T, Bautista CT, Garuchava N, Sanodze L, Kokaia N, Malania L, et al.
Epidemiological and clinical features of brucellosis in the country of Georgia. PLoS One. 2017;12(1):e0170376.

25. Li MT, Sun GQ Zhang WY, Jin Z. Modelbased evaluation of strategies to control brucellosis in China. Int J Environ Res Public Health. 2017;14(3):295.

26. Akbayram S, Dogan M, Akgun C, Peker E, Parlak M, Oner AF. An analysis of children with brucellosis associated with isolated thrombocytopenia. Clin Appl Thromb 